\title{
The Newborn of Diabetic Rat. I. Hormonal and Metabolic Changes in the Postnatal Period
}

\author{
JOSE M. CUEZVA, ${ }^{(51)}$ EDWARD S. BURKETT, DOUGLAS S. KERR, HARVEY M. RODMAN, AND \\ MULCHAND S. PATEL ${ }^{(5.2)}$ \\ Departments of Biochemistry, Nutrition, Pediatrics and Medicine and Clinical Research Center, Case Western Reserve \\ University School of Medicine, Cleveland, Ohio, USA
}

\section{Summary}

In this study we investigated the effects of streptozotocin-induced maternal diabetes on fetal body weight and alterations in the plasma concentrations of glucose, insulin, glucagon and catecholamines, and in the concentrations of pancreatic insulin and glucagon and of hepatic glycogen and cAMP in newborn rats during the first $6 \mathrm{~h}$ of life. Hyperglycemia was regulated in one group of diabetic pregnant rats by administration of insulin twice a day from day 18 of gestation. On day 22 of gestation the body weight of newborns of the insulin-treated diabetic rats was significantly higher than that of normal rats, whereas untreated maternal diabetes caused a reduction in the body weight of the newborns. The newborns of insulin-treated diabetic rats maintained lower concentrations of plasma glucose for a longer period compared to the age-matched neonates of normal rats.

At birth and during the first 6 postnatal h of life, plasma insulin was significantly higher in the neonates of both treated and untreated diabetic rats than the age-matched pups of normal rats. There was an increase in the concentration of plasma pancreatic glucagon in the newborns of normal rats within $\mathbf{3 0}$ min after birth, in contrast, a gradual reduction or no change in the concentrations of plasma glucagon was observed in the neonates of both groups of diabetic rats during the $6 \mathrm{~h}$ postnatal period. The concentrations of plasma epinephrine and norepinephrine were very high at birth in the three groups of newborns, and declined rapidly during the first postnatal $h$. Significant secondary increases in the concentrations of these two hormones occurred in the three groups of neonates after the plasma glucose concentration had declined to below $2 \mathrm{mM}$. Changes in the insulin:glucagon molar ratio was associated with a delay in the postnatal increase in hepatic cAMP concentrations and also in the initiation of hepatic glycogenolysis in the neonates of both groups of diabetic rats compared to normal animals. The findings of macrosomia, postnatal hyperinsulinemia, prolonged lowered plasma glucose and attenuated plasma glucagon observed in the newborns of the insulin-treated diabetic rats are similar to the findings reported in the newborn infants of insulin-dependent diabetic women.

\section{Speculation}

Diabetes during pregnancy in the rats described in this study is reproducible and can be regulated with insulin administration. This experimental model should prove useful in quantifying alterations in hepatic glycogen metabolism and gluconeogenesis, and the mechanism(s) responsible for the attenuated glucagon secretory response in newborns of diabetic mothers.

Hormonal and metabolic adaptations in the normal newborn rat in the immediate postnatal period have been studied extensively and reviewed frequently $(2,12,18)$. Similar studies in the newborn of diabetic mothers in this species are few in number and limited in intent. Studies reported so far have been concerned primarily with the effects of maternal diabetes on fetal growth (14,
$15,22,28,29)$ or its influence on fetal plasma and pancreatic insulin concentrations $(15,19,21)$. Studies on the infants of diabetic mothers have contributed to our understanding of metabolic adaptations in the postnatal period, but are limited to measuring the concentrations of hormones and substrates in the plasma $(1,24)$. Our interest in metabolic adaptations during the immediate postnatal period in the newborn rat has led us to examine possible alterations in these adaptations in the newborns of mildly and severely hyperglycemic rats. The goals of this study were to characterize changes in the concentrations of plasma insulin, glucagon, catecholamines and glucose in the newborns of normal and diabetic rats during the first $6 \mathrm{~h}$ of postnatal life, and to compare them with changes in the concentrations of insulin and glucagon in the pancreases and of cAMP and glycogen in the livers.

\section{MATERIALS AND METHODS}

Animals. Timed pregnant Sprague-Dawley rats (overnight mating) (38) weighing $200 \mathrm{~g}$ were fed Purina Laboratory Chow and water ad libitum. Diabetes was induced by injecting streptozotocin ( $45 \mathrm{mg} / \mathrm{kg}$ of body weight) in $50 \mathrm{mM}$ sodium citrate buffer, $\mathrm{pH}$ 4.5 , into the tail vein of pregnant rats on day 5 of gestation (14). Controls were injected with buffer alone. Diabetes was confirmed $48 \mathrm{~h}$ after streptozotocin administration by measuring tail vein blood glucose (4). An animal was designated as severely diabetic when its mean blood glucose concentration was $15 \mathrm{mM}(270 \mathrm{mg} /$ $\mathrm{dl}$ ) or higher from days 7 to 22 of gestation, in accordance with a previous report (19). Measurements of blood glucose were made at $0900 \mathrm{~h}$ at intervals of 3-4 days during the entire period of gestation. A group of diabetic pregnant rats with severe hyperglycemia were treated by two daily subcutaneous injections of NPHinsulin (39) from day 18 of gestation until delivery. Insulin treatment was initiated on day 18 of gestation because the development of the fetal pancreas and fetal plasma insulin concentrations were found to increase markedly from day 18 until birth in the rat (13, 31). Diabetic rats were injected with 1-2 units of insulin at 0900 h ( 1 unit per every $100 \mathrm{mg}$ of glucose above the first $100 \mathrm{mg} / 100$ $\mathrm{ml}$ of blood) and 2-4 units at $1700 \mathrm{~h}$ ( 2 units per every $100 \mathrm{mg}$ of glucose above the first $100 \mathrm{mg} / 100 \mathrm{ml}$ of blood). To determine the dose, tail vein blood glucose was measured twice daily in the insulin-treated animals immediately before the injection of insulin. This regimen of insulin administration reduced the blood glucose concentration from severely hyperglycemic $(270 \mathrm{mg} / \mathrm{dl}$ or higher $)$ to mildly hyperglycemic values (from $80-200 \mathrm{mg} / \mathrm{dl}$ ) in treated rats. This treatment was not designed to completely normalize blood glucose concentrations in diabetic rats during the entire treatment. In one study when glucose concentrations were measured every $2 \mathrm{~h}$ after insulin administration at $1700 \mathrm{~h}$, we observed that treatment lowered the blood glucose concentration to the normal range within $1-2 \mathrm{~h}$, followed by a gradual increase in the concentration of blood glucose after about $6 \mathrm{~h}$. In another group of treated rats the mean blood glucose was $12.3 \pm 1.2 \mathrm{mM}$ immediately before and $5.7 \pm 0.9 \mathrm{mM} 4 \mathrm{~h}$ after insulin adminis- 
tration at $0900 \mathrm{~h}$. The degree of hyperglycemia observed in the untreated diabetic rats and the insulin treatment described above were well tolerated and no mortality occurred in the two groups of rats.

Postnatal studies. Term fetuses were delivered with intact placentas by rapid hysterectomy of cervically dislocated mothers on 22 days of gestation at $1000 \mathrm{~h}$. Pregnant rats in our colony, if allowed, delivered pups about $8 \mathrm{~h}$ later. Newborns were quickly detached after tying the umbilical cords and maintained at $37^{\circ} \mathrm{C}$ in a humidicrib with a water saturated atmosphere and without feeding (8). At birth $(0 \mathrm{~h})$ the plasma and livers of the first two fetuses still attached to the mother were removed within $30 \mathrm{sec}$ after killing her. Fetuses or newborn rats were killed by decapitation and $100 \mu \mathrm{l}$ of blood from each pup was collected and quickly mixed with $100 \mu \mathrm{l}$ of ice cold normal saline solution containing 1000 units of Trasylol (40) and $0.24 \mathrm{mg}$ of EDTA. Plasma was separated by centrifugation in the cold and the samples stored at $-70^{\circ} \mathrm{C}$ until assayed for insulin (16) and glucagon $(10,41,42)$ by radioimmunoassay techniques. The concentrations of insulin and glucagon were calculated using rat insulin (43) and porcine glucagon as standards. Plasma glucose was assayed with a Beckman Glucose Analyzer. The pancreases were removed from fetuses and newborns, and extracted with an acid alcohol solution for hormone determination (30). For catecholamines, $100 \mu \mathrm{l}$ of blood were mixed with an equal volume of ice cold saline containing $5 \mathrm{mM}$ EGTA and $4 \mathrm{mM}$ glutathione. After centrifugation the plasma was stored at $-70^{\circ} \mathrm{C}$ until assayed for catecholamines using a radioenzymatic method with catechol-Omethyl transferase and $\left[{ }^{3} \mathrm{H}\right]-\mathrm{CH}_{3}$-S-adenosylmethionine $(26,44)$. For cAMP extraction and measurement $(6,45)$ the livers of the fetuses and newborn rats were freeze-clamped before decapitation of the pups. Glycogen content in livers and placentas was measured by the method of Van Handel (36). Statistical analysis was performed by the Student's $t$ test for non-paired samples, and comparison was made with the control group. $P$ values of 0.05 or less were taken as significant, and the results are expressed as the mean \pm S.E.

Histologic and immunocytochemical studies (46). Fragments of pancreas from all three experimental groups were fixed in Bouin's fluid overnight. Following repeated washings in $70 \%$ ethanol the tissue was embedded in paraffin and multiple serial sections, $6 \mu \mathrm{m}$ in thickness were obtained. One section was stained with hematoxylin and eosin whereas four adjacent sections were used for the immunocytochemical localization of insulin, glucagon, pancreatic polypeptide and somatostatin, respectively. The peroxidase-antiperoxidase (PAP) procedure using rabbit antisera to glucagon (42), pancreatic polypeptide (47) and somatostatin (48) as primary antibody, goat anti-rabbit $\operatorname{IgG}(49)$ as a link antibody and rabbit PAP (49) was applied as described by Sternberger (34). For the localization of insulin, guinea pig anti-insulin serum (49) was linked to rabbit PAP by means of staphylococcal protein A according to previously reported procedures $(7,23)$. The specificity of the immunostaining was verified by replacing the primary antiserum with normal rabbit serum or normal guinea pig serum. For control purposes, pancreases of normal adult female rats, identically fixed and processed were immunostained applying the same antisera and identical procedures.

\section{RESULTS}

Experimental animals. The effects of mild or severe maternal hyperglycemia on maternal weight gain during pregnancy, newborn weight, hepatic glycogen content, and placental weight and glycogen content are shown in Table 1 . In the untreated diabetic mothers severe hyperglycemia had no effect on weight gain during gestation. Maternal weight gain of the insulin-treated diabetic rats was significantly increased compared to normal pregnant rats. The body weight of the newborn pups of untreated diabetic mothers was significantly reduced whereas the body weight of the newborns of the insulin-treated diabetic rats was heavier than that of normal rats. Liver glycogen content was significantly increased in the newborn pups of the untreated diabetic mothers compared to normals (Table 1); however, hepatic glycogen content of the newborns of the insulin-treated diabetic mothers was not significantly different from that observed in the newborns of normal animals. There was a significant increase in placental weights and the glycogen concentration of the placentas from both groups of diabetic rats compared to normal animals (Table 1).

Changes in plasma glucose concentrations. Figure 1 illustrates the changes in the concentration of plasma glucose over the first $6 \mathrm{~h}$ of life in the pups of the normal and diabetic rats. The plasma

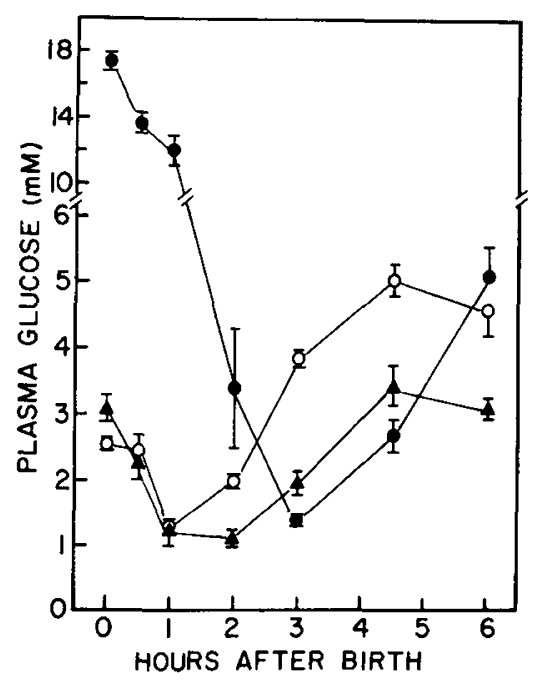

Fig. 1. Plasma glucose concentrations in newborns of normal $(O)$, untreated diabetic $(\boldsymbol{O})$, and insulin treated diabetic $(\boldsymbol{\Delta})$ rats during the first 6 postnatal $h$. The results are the means \pm S.E. for ten to twelve neonates from five to six mothers.

Table 1. Effect of maternal diabetes mellitus on fetal growth and glycogen concentration of fetal liver and placentas on day 22 of gestation

\begin{tabular}{|c|c|c|c|c|c|c|}
\hline \multicolumn{3}{|c|}{ Mothers } & \multicolumn{2}{|c|}{ Newborns } & \multicolumn{2}{|c|}{ Placentas } \\
\hline Status & $\begin{array}{l}\text { Blood glucose } \\
(\mathrm{mM})\end{array}$ & $\begin{array}{c}\text { Weight gain } \\
(\mathrm{g})\end{array}$ & $\begin{array}{l}\text { Weight } \\
\text { (g) }\end{array}$ & $\begin{array}{c}\text { Liver glycogen } \\
(\mu \mathrm{mole} / \mathrm{g})\end{array}$ & $\begin{array}{l}\text { Weight } \\
\text { (mg) }\end{array}$ & $\begin{array}{l}\text { Glycogen } \\
(\mu \text { mole } / g)\end{array}$ \\
\hline Normal & $4.9 \pm 0.1(15)$ & $124 \pm 4$ & $5.50 \pm 0.06$ & $522 \pm 21$ & $551 \pm 12$ & $9 \pm 1$ \\
\hline Untreated diabetic & $18.6 \pm 0.6(13)^{4}$ & $120 \pm 5$ & $5.25 \pm 0.11^{1}$ & $663 \pm 29^{2}$ & $604 \pm 15^{3}$ & $36 \pm 2^{4}$ \\
\hline Insulin treated diabetic & $7.1 \pm 0.2(24)^{4}$ & $139 \pm 7^{1}$ & $5.84 \pm 0.06^{4}$ & $573 \pm 33$ & $644 \pm 15^{4}$ & $24 \pm 1^{4}$ \\
\hline
\end{tabular}

The weight gain of pregnant rats was measured from day 5 to day 22 of gestation. Glycogen concentration expressed as $\mu$ mole/g represents $\mu$ moles of glucosyl residues per $\mathrm{g}$ wet weight of the tissue. The results are the means \pm S.E. of the number of mothers shown in parentheses.

i $P<0.05$ compared with normal.

$\therefore P<0.01$ compared with normal.

${ }^{3} P<0.005$ compared with normal.

${ }^{4} P<0.001$ compared with normal. 
glucose concentration in the newborns of normal rats decreased to $1.4 \pm 0.1 \mathrm{mM}$ at $1 \mathrm{~h}$ after birth, and increased to $3.8 \pm 0.2 \mathrm{mM}$ at the third $h$ of life. Plasma glucose was higher during the subsequent $3 \mathrm{~h}$ of postnatal life. In the newborns of untreated diabetic rats plasma glucose was $17.4 \pm 0.6 \mathrm{mM}$ at birth and declined rapidly, reaching a level of $1.4 \pm 0.1 \mathrm{mM}$ at $3 \mathrm{~h}$ of age. Plasma glucose increased gradually over the next $3 \mathrm{~h}$ of life reaching a level of $5.1 \pm 0.5 \mathrm{mM}$ at the sixth postnatal $\mathrm{h}$. In the pups of insulin-treated diabetic animals plasma glucose remained lower (approximately $1 \mathrm{mM}$ ) for a longer period of time compared to the age-matched normal pups.

Changes in plasma insulin and glucagon concentrations. Figure 2 illustrates the plasma insulin concentrations of the newborn pups of normal, untreated and insulin-treated diabetic rats. At the time of delivery by cesarean section, the plasma insulin concentration was significantly higher in the two groups of newborns of diabetic rats than in the normal pups at birth. It took one-half $h$ longer for the plasma insulin concentration to decline in the newborns of the insulin-treated diabetic rats compared to the two other groups of newborns. The insert in Figure 2 illustrates that plasma insulin concentrations in the newborns of both groups of diabetic mothers remained significantly higher than in the aged-matched normal pups during the last $4 \mathrm{~h}$ of the study.

At birth the concentration of plasma glucagon was higher in the newborns of untreated diabetic mothers compared to normals $(P<0.005)$ (Fig. 3). A significant increase in plasma glucagon was observed in the neonates of normal rats 30 min after birth $(P$ $<0.001$ ) and this elevation was maintained during the 6 postnatal $\mathrm{h}$ of life. There was a significant gradual reduction of the plasma glucagon concentration in the neonates of untreated diabetic rats during the first $3 \mathrm{~h}$ of life. The neonates of untreated diabetic mothers experienced a decline in their plasma glucagon during the first $h$ of life and maintained this low concentration of the hormone for the subsequent $5 \mathrm{~h}$ of life. It is noteworthy that at the third $h$ of life, the mean plasma glucagon concentration in the pups of normal rats was approximately twice the concentrations measured in the age-matched pups of the two groups of diabetic animals. The change in the insulin/glucagon molar ratio for each group of neonates was similar to the change in the plasma insulin concentrations observed in the corresponding group of pups (results not shown). The newborns of both groups of diabetic rats maintained higher insulin/glucagon molar ratios than those of the neonates of the normal rats (results not shown).

Changes in pancreatic insulin and glucagon concentrations. The histologic and immunocytochemical study of the fetal pancreases did not reveal significant differences in islet morphology, cell type composition or distribution among the three experimental groups. No adverse effect on the morphology of insulin-positive cells was observed in the pancreases of fetuses whose mothers were treated with streptozotocin during pregnancy. At birth the pancreatic insulin content in the newborns of normal rats was significantly

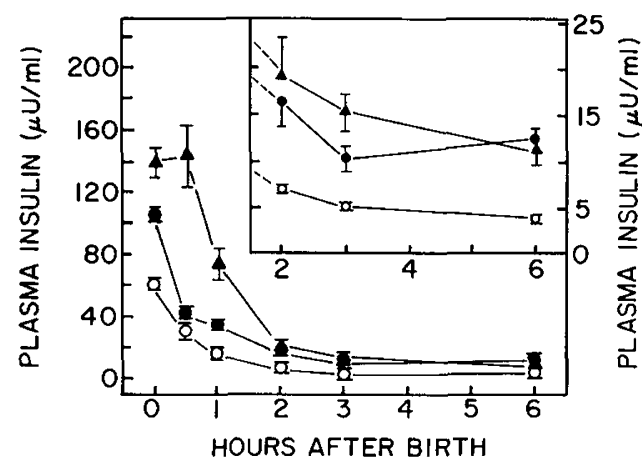

Fig. 2. Plasma insulin concentrations in the newborns of normal $(O)$, untreated diabetic $(\boldsymbol{O})$, and insulin treated diabetic $(\boldsymbol{\Delta})$ rats during the first 6 postnatal $h$. Insert shows, on an expanded scale, the concentrations of plasma insulin in the neonates from 2-6 postnatal $h$. The results are the means $\pm \mathrm{S}$.E. for eight to twelve neonates from four to six mothers.

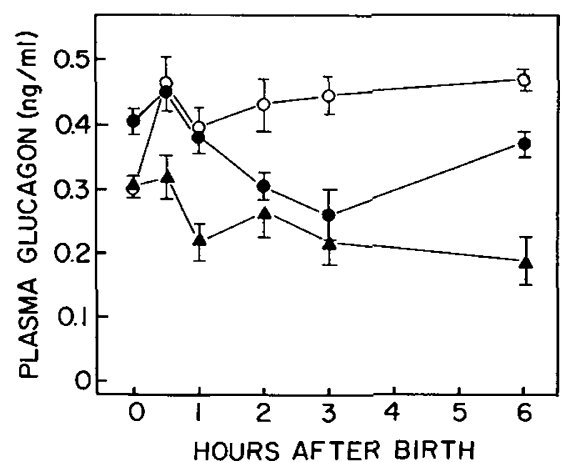

Fig. 3. Plasma pancreatic glucagon concentrations in the newborns of normal $(\bigcirc)$, untreated diabetic $(\boldsymbol{O})$, and insulin treated diabetic $(\boldsymbol{\Delta})$ rats during the first 6 postnatal $h$. The results are the means $\pm S$.E. for eight to twelve neonates from four to six mothers.

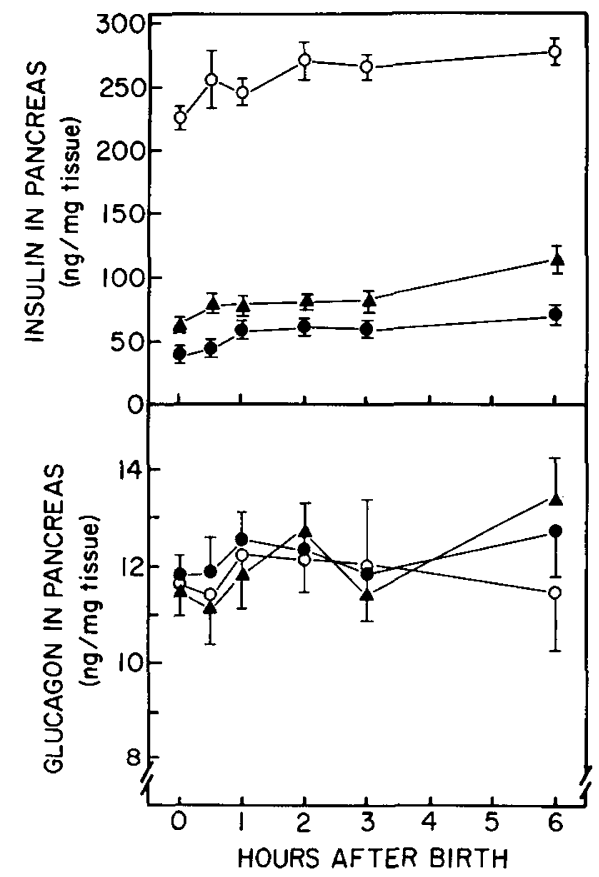

Fig. 4. Insulin and glucagon concentrations in the pancreases of newborns of normal $(O)$, untreated diabetic $(O)$, and insulin treated diabetic (A) rats. The results are the means \pm S.E. for eight to twelve neonates from four to six mothers.

higher than that observed in the newborns of both mildly and severely hyperglycemic rats, and these differences were maintained during the first $6 \mathrm{~h}$ of postnatal life (Fig. 4). In the first 6 postnatal $h$ of life, a small but significant increase in pancreatic insulin content was observed in all three groups of neonates compared to their insulin concentrations at birth (Fig. 4). At birth pancreatic glucagon content was similar in the newborns of the three groups of rats (Fig. 4), and all three groups of neonates maintained a similar concentration of glucagon in the pancreas during the $6 \mathrm{~h}$ postnatal period.

Changes in plasma catecholamines. The concentrations of both epinephrine and norepinephrine in plasma were very high at the time of delivery in the three groups of newborns and declined rapidly during the first postnatal $h$. The rate of decline was more rapid in the newborns of normal and untreated diabetic rats compared to insulin-treated diabetic rats (Fig. 5). During the second postnatal $h$, a secondary increase in the concentrations of plasma epinephrine and norepinephrine was observed in the newborns of normal rats $(P<0.05)$ but not in the other two groups. The concentration of plasma norepinephrine but not epinephrine, increased significantly $(P<0.005)$ in the neonates of 


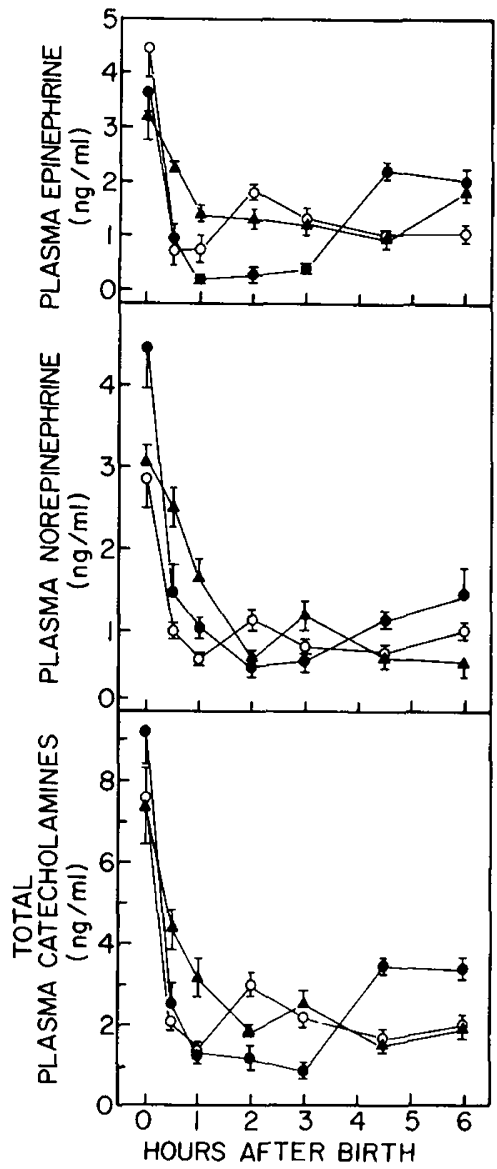

Fig. 5. Plasma concentrations of epinephrine. norepinephrine and total catecholamines (epinephrine plus norepinephrine) in the newborns of normal $(\bigcirc)$, untreated diabetic $(\bigcirc)$, and insulin treated diabetic $(\mathbf{\Delta})$ rats during the first 6 postnatal $h$. The results are the means of S.E. for eight to twelve neonates from four to six mothers.

insulin-treated diabetic rats between the second and third postnatal h (Fig. 5). A significant increase in the concentrations of both hormones was observed in neonates of untreated diabetic rats at $4.5 \mathrm{~h}$ after birth. The secondary increases in plasma catecholamines in each group followed the nadir of plasma glucose and were associated with an increase in plasma glucose.

Changes in the concentrations of glycogen and CAMP in the liver. Figure 6 illustrates liver glycogen concentration in the three groups of neonates. At birth hepatic glycogen concentration was significantly increased in the pups of untreated diabetic rats compared to the offspring of normal and insulin-treated diabetic rats. A significant reduction $(P<0.05)$ in the liver glycogen concentration of the neonates of normal rats was initially observed at the second postnatal $\mathrm{h}$, and declined steadily over the next $4 \mathrm{~h}$ of life. A significant decline in hepatic glycogen concentration of the neonates of insulin-treated diabetic rats was first observed during the third postnatal $\mathrm{h}$. In the neonates of untreated diabetic rats, the reduction of hepatic glycogen concentration did not occur until at the fourth postnatal $h$ of life. In each group the time of decline of hepatic glycogen concentration coincided with the time of increase of plasma glucose.

At birth the hepatic concentration of cAMP in newborns of untreated diabetic rats was significantly lower than that observed in the newborns of normal animals (Fig. 7). An initial decline in hepatic cAMP in the neonates of normal rats occurred at $30 \mathrm{~min}$ of life and was followed by a significant increase over the next $h$ and a half of postnatal life. In contrast, the concentration of CAMP in the neonates of the untreated diabetic rats declined significantly $(P<0.005)$ during the second postnatal h. A marked increase in the hepatic concentration of cAMP was observed in this group of pups at the third postnatal $h$ (Fig. 7). The concentration of cAMP in the livers of neonates of insulin-treated diabetic rats did not change during the first two postnatal h; however, a significant increase in the hepatic cAMP concentration in this group of neonates was observed at the third postnatal $h$. There was no significant difference in hepatic cAMP concentration among the neonates of normal, untreated and insulin-treated diabetic rats at either the third or the sixth postnatal h of life (Fig. 7).

\section{DISCUSSION}

Fetal hyperinsulinemia secondary to maternal hyperglycemia is generally accepted as the mechanism responsible for the higher birth weight and the increased total body fat, glycogen, and nitrogen in the newborn infants of diabetic mothers $(17,25)$. In the rat, the effect of diabetic pregnancy on the body weight of the offspring remains controversial. Conflicting reports have varied

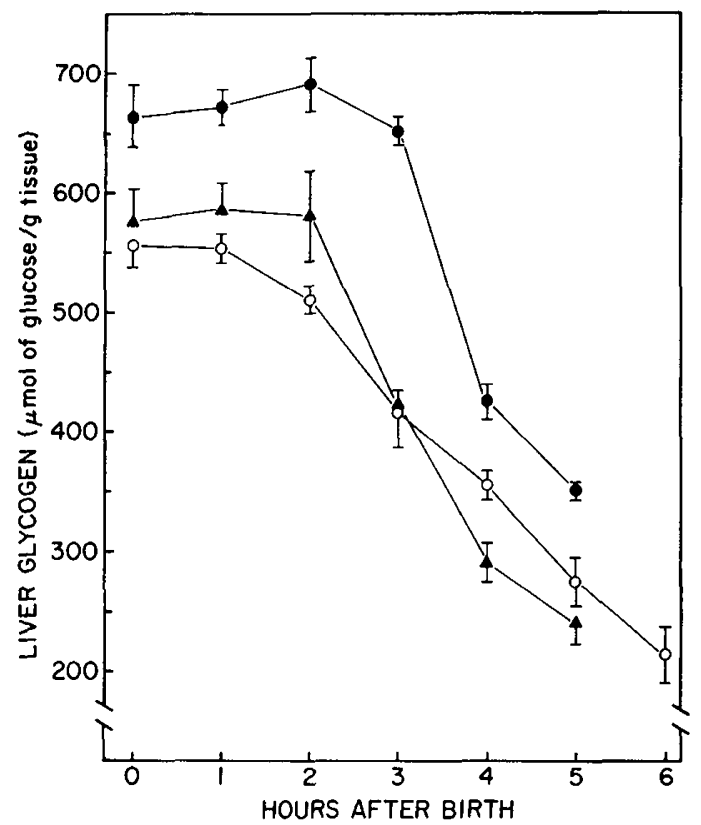

Fig. 6. Liver glycogen concentrations in newborns of normal $(O)$, untreated diabetic $(\mathbf{O})$, and insulin treated diabetic $(\boldsymbol{\Delta})$ rats during the first 6 postnatal $h$. The results are the meais $\pm S$.E. for eight to twelve neonates from four to six mothers.

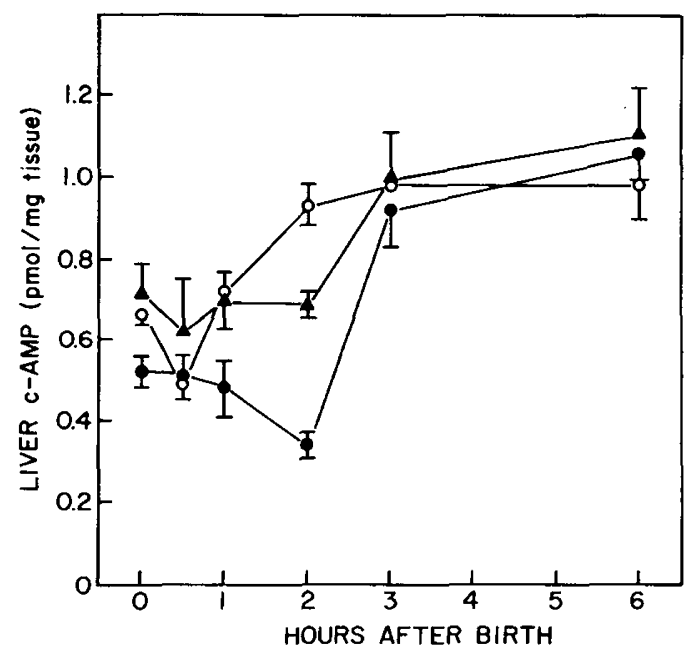

Fig. 7. Liver cAMP concentrations in newborns of normal $(O)$, untreated diabetic $(\bullet)$, and insulin treated diabetic $(\boldsymbol{\Delta})$ rats during the first 6 postnatal $h$. The results are the means \pm S.E. from eight to fourteen neonates from four to seven mothers. 
from no change in weight compared to the neonates of normal animals (29), to a decrease $(14,29)$, or to an increase in weight $(20,28,35)$. Our finding of decreased weight in the newborns (22day-old term fetuses) of untreated diabetic animals agrees with the similar finding reported by Kervran et al. (19). Our finding of increased neonatal weight in the pups of insulin-treated diabetic rats also agrees with others who found increased weight in the newborns (22-day-old fetuses) from mildly diabetic pregnant rats $(28,35)$. Kim et al. $(20)$ have recently observed an increase in the mean gestational period of the severely diabetic animals thus explaining the increase in the body weights of their newborns by natural delivery.

An interesting observation with respect to offspring weight was that the administration of insulin twice daily during the last 5 days of gestation to diabetic rats was associated with macrosomic offspring compared to those of normal animals (Table 1). The effects of mild hyperglycemia on various parameters studied in the newborns in this report have not been previously examined in the rat.

In the present study, hyperinsulinemia was noted at term in the newborns of mildly hyperglycemic (insulin-treated) and severely hyperglycemic (untreated) diabetic rats compared to the values found in the offspring of normal rats; however, at birth, the concentration of plasma insulin in the newborns of insulin-treated diabetic animals was significantly higher than that observed in the newborns of untreated diabetic animals (Fig. 2). Available reports concerning plasma insulin concentration in the newborns of diabetic rats are restricted to the values measured at birth $(15,19)$; no previous study has measured concentrations of plasma insulin serially during the first 6 postnatal h of life. For example, Kervran and colleagues (19) reported hyperinsulinemia in the term fetuses of mildly hyperglycemic diabetic rats at birth, but found normal plasma insulin concentrations in the term fetuses of severely hyperglycemic diabetic rats. Pitkin and Van Orden (29) found an increase in plasma insulin concentration at birth of term fetuses from mothers with mild and severe hyperglycemia, defined by blood glucose concentrations of 150 and $218 \mathrm{mg} / \mathrm{dl}$, respectively; however, according to the distinctions made by Kervran et al. (19) and in the present study, the maternal glucose concentrations of both groups of rats studied by Pitkin and Van Orden (29) represent mild hyperglycemia. We cannot explain the differences observed by Kervran and colleagues (19) and ourselves with certainty; however, we found that the newborns of severely hyperglycemic mothers had hyperinsulinemia not only at birth but also during hourly measurements made during the first $6 \mathrm{~h}$ of life. It was of interest that our insulin-treated diabetic rats (who were intermittently mildly hyperglycemic) gave birth to offspring who maintained hyperinsulinemia during the first $6 \mathrm{~h}$ of life. Because the newborns (22-day-old fetuses) of the two groups of diabetic rats had plasma hyperinsulinemia compared to the newborns of normal rats (Fig. 3), the results suggest that the 22-day-old fetuses of the diabetic rats continuously secreted their newly synthesized pancreatic insulin in response to fetal hyperglycemia, and hence had lower concentrations of insulin in their pancreas (Fig. 4). In contrast, Kervran et al. (19) found higher concentrations of insulin in the pancreas of the fetuses of mildly diabetic rats compared to normal animals. Although the reason for this discrepancy is not clear, the degree of maternal hyperglycemia during several $h$ before killing may have been a contributing factor in these two studies.

Other interesting observations made in this study included the changes in plasma glucagon concentration at birth and during the first $6 \mathrm{~h}$ of life in the newborns of normal and diabetic rats. A significant increase in the plasma concentration of glucagon was observed only in the neonates of the normal rats during the early postnatal period. The concentrations of plasma glucagon in the newborns of mildly and severely hyperglycemic rats remained either unchanged or declined significantly compared to the agematched pups of normal animals during the first 6 postnatal $h$ (Fig. 3). These observations were in agreement with the clinical findings that the concentration of plasma glucagon in the 2-hour- old infants of insulin-dependent diabetic mothers was lower than that in normal infants and failed to increase in response to hypoglycemia $(5,37)$. Relatively higher concentrations of insulin and lower values of plasma glucagon and hence higher insulin/ glucagon molar ratios in the neonates of insulin-treated diabetic rats compared to the ratios in the newborns of normal animals probably contributed to the delay in the initiation of glycogen degradation (Fig. 6) and the prolonged postnatal hypoglycemia observed in this group of newborns (Fig. 1).

In spite of the lack of the postnatal glucagon secretory response, a significant increase in the concentrations of hepatic cAMP in the neonates of diabetic rats was observed during the third postnatal $h$ (Fig. 7), and this increment was comparable to a similar response during the first $2 \mathrm{~h}$ in the newborns of normal rats. Although the administration of exogenous epinephrine is shown to cause a marked increase in the concentration of hepatic cAMP in 2-day-old normal rats (9), very little is known about the alterations in the concentrations in plasma catecholamines in the newborns of rats during the first $24 \mathrm{~h}$ period (3). Until now it was, however, not possible to study independently the effect of glucagon or catecholamines on hepatic cAMP concentrations in the newborn rat. In the present study, the newborns of untreated and insulin-treated diabetic rats provided a unique opportunity to investigate the effect of plasma catecholamines on the concentrations of hepatic cAMP (in the absence of a postnatal increase in the concentration of plasma pancreatic glucagon). The increase in the concentration of hepatic cAMP in the neonates of insulintreated diabetic rats (Fig. 5) paralleled the increase in plasma norepinephrine in these pups during the third postnatal h (Fig. 7); however, hepatic cAMP increased before the secondary increase of plasma catecholamines in the neonates of untreated diabetic rats. A secondary increase in plasma catecholamines was observed in all three groups of neonates after the plasma glucose concentration declined to minimum levels (less than $2 \mathrm{mM}$ ), and the secondary rise in catecholamines was associated with an increase of plasma glucose and decrease of hepatic glycogen. This is consistent with a recent report (27) showing that insulin-induced hypoglycemia in term pregnant rats causes an increase in the concentrations of plasma catecholamines in both term fetuses and pregnant rats. Our findings suggest that the endogenous catecholamines could contribute to the regulation of plasma glucose in newborn rats; however, additional signals (other than glucagon or catecholamine) also appear to influence cAMP concentrations in the liver.

The data presented in this study concerning the postnatal changes in plasma glucose, hepatic glycogen, and liver cAMP concentrations in the neonates of normal rats are similar to previous reports $(9,11)$. The higher concentrations of hepatic glycogen in the 22-day-old fetuses of severely hyperglycemic rats were due to their hyperinsulinemia and severe hyperglycemia. High concentrations of insulin and glucose are known to increase glycogen synthetase $I$ activity and to decrease hepatic phosphorylase $a$ activity in perfused fetal monkey liver (33) and in the newborns of diabetic rats (32). The delay in the initiation of hepatic glycogenolysis in the neonates of the diabetic rats was probably due to their hyperinsulinemia, which persisted during the early postnatal $h$. Although the concentrations of plasma glucagon in the neonates of untreated and insulin-treated diabetic rats declined significantly during the first 3 postnatal $h$, a significant increase in the concentrations of hepatic cAMP was observed in these two groups of pups during the third postnatal $h$. The increase in hepatic cAMP concentrations in the newborns of untreated and insulin-treated diabetic rats preceded the initiation of hepatic glycogenolysis.

The data presented in this study are the first documentation of sequential changes in the concentrations of insulin, glucagon and catecholamines in the plasma and of cAMP and glycogen in the livers of the newborns of mildly and severely hyperglycemic animals in the immediate postnatal period. The postnatal changes in the plasma concentrations of glucose, insulin, and glucagon in the newborns of insulin-treated diabetic rats in this study closely 
parallel those observed by others in the newborn infants of insulindependent human diabetic mothers.

\section{REFERENCES AND NOTES}

1. Adam. P. A. J. and Felig. P.: Carbohydrate, fat. and amino acid metabolism in the pregnant woman and fetus. In: F. Falkner, and J. M. Tanner: Human Growth. Vol. I. pp. 461-547 (Plenum Publishing Corp.. New York. 1978).

2. Ballard. F. J.: Carbohydrate metabolism and the regulation of blood glucose. In U. Stave: Perinatal Physiology. pp. 365-381 (Plenum Medical Book Company. New York. 1978).

3. Ben-Jonathan. N.: Plasma catecholamine in fetal and neonatal rats. Life Sci.. 23: 39 (1978).

4. Bergmeyer, H. V.. Bernt, E.. Schmidt. F.. and Stork, H.: D-glucose determination with hexokinase and glucose-6-phosphate dehydrogenase. In: H. V. Bergmeyer: Methods in Enzymatic Analysis. Vol. 3. pp. 1196-1201 (Academic Press. New York, 1974).

5. Bloom. S. R. and Johnston. D. I.: Failure of glucagon release in infants of diabetic mothers. Brit. Med. J., 4: 453 (1972).

6. Brown. B. L.. Albano, J. D. M., Ekins. R. P., Sgherzi. A. M., and Tampion, W.: A simple and sensitive saturation assay method for the measurement of adenosine 3':5'-cyclic monophosphate. Biochem. J.. 121: 561 (1971)

7. Celio, M. R., Lutz, H., Binz. H., and Fey, H.: Protein A in immunoperoxidase techniques. J. Histochem. Cytochem.. 27: 691 (1979)

8. Cuezva. J. M., Morano. F. J., Medina, J. M., and Mayor, F.: Prematurity in the rat. I. Fuels and gluconeogenic enzymes. Biol. Neonates, 37: 88 (1980).

9. DiMarco, P. N. and Oliver. 1. T.: Adenosine $3^{\prime}: 5^{\prime}-$ Monophosphate in perinata rat liver. Ontogeny and response to hormones. Eur. J. Biochem., 87: 235 (1978).

10. Faloona. G. R.. Bottger. I.. and Eisentraut, A. M.: Radioimmunoassay of glucagon in plasma. In: H. Breuer, D. Hamel, and H. L. Kruskemper: Methods of Hormone Analysis, pp. 111-117 (John Wiley and Sons, New York, 1976).

11. Girard, J. R.. Cuendet, G. S., Marliss, E. B.. Kervran. A.. Rieutort. M., and Assan. R.: Fuels, hormones and liver metabolism at term and during the early postnatal period in the rat. J. Clin. Invest., 52: 3190 (1973).

12. Girard. J.. Ferre. P.. Pegorier, J-P.. Leturque, A., and Callikan. S.: Factors involved in the development of hypoglycemia in fasting newborn rats. In: D. Andreani. P. J. Letebvre, and V. Marks: Current views on hypoglycemia and glucagon. Proceedings of the Serono Symposia. Vol. 30,pp. 343-353 (Academic Press. London. 1980).

13. Girard. J. R.. Kervran, A.. Soufflet. E.. and Assan, R.: Factors affecting the secretion of insulin and glucagon by the rat fetus. Diabetes, 23: 310 (1974).

14. Golob, E. K.. Rishi. S.. Becker, K. L., and Moore, C.: Streptozotocin diabetes in pregnant and nonpregnant rats. Metabolism, 19: 1014 (1970).

15. Golob E. K.. Rishi. S.. Becker. K. L.. Moore, C.. and Shah. N.: Effect of streptozotocin-induced diabetes on pancreatic insulin content of the fetus. Diabetes, 14: 610 (1970)

16. Herbert. V.. Lau. K. S.. Gottlieb, C. W., and Bleicher. S. J.: Coated charcoal immunoassay of insulin. J. Clin. Endocr. Metab., 25: 1375 (1965).

17. Hill, D. E.: Effect of insulin on fetal growth. Seminars in Perinatology, 2: 319 (1978).

18. Jost. A. and Picon. L.: Hormonal control of fetal development and metabolism. In: R. Levine, and R. Luft: Advances in Metabolic Disorders, Vol. 4, pp. 123-184 (Academic Press, New York, 1974).

19. Kervran. A.. Guillaume. M.. and Jost. A.: The endocrine pancreas of the fetu from diabetic pregnant rat. Diabetologia. 15: 387 (1978).

20. Kim. Y. S., Jatoi. I., and Kim. Y.: Neonatal marcosomia in maternal diabetes. Diabetologia, 18: 407 (1980)

21. Kim. J. N., Runge. W.. Wells, L. J., and Lazarow. A.: Pancreatic islets and blood sugars in prenatal and postnatal of fspring from diabetic rats: Beta granulation and glycogen infiltration. Anat Rec., 138: 239 (1960).

22. Lazarow. A., Kim, J. N., and Wells, L. J.: Birth weight and fetal mortality in pregnant subdiabetic rats. Diabetes. 9: 114 (1960).

23. Notiani. G. W.. Parsons. J. A.. and Erlandsen. S. L.: Versatility of Staphylococcus aureus protein $\mathrm{A}$ in immunocytochemistry. Used in unlabeled antibody enzyme system and fluorescent methods. J. Histochem. Cytochem.. 27: 1438 (1974).
24. Pedersen. J.: Fetal Macrosomia. In: H. W. Sutherland. and J. M. Stowers: Carbohydrate Metabolism in Pregnancy and the Newborn. pp. 127-139 (Churchill Livingstone, London, 1975).

25. Pedersen, J. and Osler, M.: Hyperglycemia as the cause of characteristic features of the foetus. Danish Med. Bull., 8: 78 (1961).

26. Peuler. J. D. and Johnson. G. A.: Simultaneous single isotope radioenzymatic assay of plasma norepinephrine, epinephrine and dopamine. Life Sci.. 21: 625 (1977).

27. Phillippe. M. and Kitzmiller, J. L.: The fetal and maternal catecholamine response to insulin-induced hypoglycemia in the rat. Am. J. Obstet. Gynecol., 1.39: 407 (1981).

28. Pitkin, R. M., Plank, C. J., and Filer, L. J.: Fetal and placental composition in experimental maternal diabetes. Proc. Soc. Exp. Biol. Med.. 183: 163 (1971).

29. Pitkiri. R. M. and Van Orden. D. E.: Fetal effects of maternal streptozotocin diabetes. Endocrinology, 94: 1247 (1974).

30. Portha. B., Rosselin, G., and Picon, L.: Postmaturity in the rat: impairment of insulin, glucagon and glycogen stores. Diabetologia, 12: 429 (1974).

31. Rishi. S., Golob, E. K., Becker, K. L., and Shah, N.: Pancreatic insulin content of nonpregnant, pregnant and postpartum rats and the developing rat fetus. Diabetes, 18: 268 (1970).

32. Singh, M. and Feigelson, M.: Development of lung carbohydrate metabolizing enzymes and glycogen stores in fetuses of diabetic mothers. Fed. Proc.. 39: $2144(1980)$

33. Sparks, J. M.. Lynch. A., and Chez. R. A.: Glycogen regulation in isolated perfused near term monkey liver. Pediatr. Res., 10:51 (1976).

34. Sternberger. L. A.: Immunocytochemistry Ed. 2. pp. 104-169 (John Wiley and Sons Inc.. New York. 1979).

35. Sybulski. S. and Maugham. G. B.: Use of streptozotocin as diabetic agent in pregnant rats. Endocrinology. 89: 1537 (1971).

36. Van Handel, E.: Estimation of glycogen in small amounts of tissue. Anal. Biochem., 11: 256 (1965).

37. Williams. P. R.. Sperling. M. A., and Racasa, Z.: Blunting of spontaneous and alanine-stimulated glucagon secretion in newborn infants of diabetic mothers. Am. J. Obst. Gynecol.. 13.3: 51 (1979).

38. Charles River Breeding Laboratories, Wilmington. MA. U.S.A

39. Insulin. NPH-Iletin. U-100 (mixture of beef and pork zinc-insulin). E. Lilly and Co.. Indianapolis. IN, U.S.A.

40. FBA Pharmaceuticals, New York, NY, U.S.A

41. I-Glucagon. Nuclear Medical Laboratory, Dallas, TX, U.S.A.

42. Antiglucagon antisera $(30 \mathrm{~K})$, Dr. R. Unger. Texas Health Sciences Center, Dallas. TX. U.S.A.

43. Rat insulin as a standard. a gift from Dr. Saul Genuth of Mt. Sinai Hospital. Cleveland, OH. U.S.A.

44. Catecholamine radioenzymatic assay kits were purchased from Upjohn Diagnostic. Kalamazoo, MI, U.S.A.

45. cAMP binding protein, a gift from Dr. Stephen Rudolph of the Department of Pharmacology, Case Western Reserve University, Cleveland. OH. U.S.A.

46. These studies were kindly performed by Dr. Manuel E. Velasco of the Institute for Pathology, Case Western Reserve University, Cleveland, OH. U.S.A

47. Rabbit antiserum to bovine pancreatic polypeptide was kindly provided by Dr. R. Chance of Eli Lilly Inc.. Indianapolis. IN. U.S.A.

48. Rabbit antiserum to synthetic somatostatin was obtained from Immunonuclear Corp.. Stillwater. MN, U.S.A.

49. Guinea pig antiserum to porcine insulin, goat antirabbit $\operatorname{IgG}$ and rabbit PAP were obtained from Cappel Laboratories, Cochranville, PA, U.S.A.

50. The authors thank Ms. Cindy Raefsky and Mrs. Marylin Levy for their skillful technical assistance.

51. J. M. Cuezva was a postdoctoral fellow of the Spanish Ministry of Universities and Research. His present address is Department of Bioquimicia y Biologia Molecular. Universidad Autonoma de Madrid. Madrid-34. Spain.

52. Request for reprints should be addressed to: Dr. M. S. Patel. Department of Biochemistry. Case Western Reserve University School of Medicine. Cleveland. $\mathrm{OH} 44106$ (U.S.A.).

53. This research was supported in part, by Public Health Service Grants HD 1162 I and HD 12643, and the Clinical Research Center Grant RR 00080.

54. Received for publication August 19.1981.

55. Accepted for publication January 15,1982 